\title{
All-trans retinoic acid enhances bystander effect of suicide gene therapy in the treatment of breast cancer
}

\author{
HENG KONG $^{1,2}$, XIA LIU $^{3}$, LIUCHENG YANG ${ }^{5}, \mathrm{KE} \mathrm{QI}^{1}$, HAOYUN ZHANG $^{1}$, \\ JINGWEN ZHANG ${ }^{4}$, ZONGHAI HUANG ${ }^{5}$ and HONGXIAN WANG ${ }^{1}$ \\ ${ }^{1}$ Department of Thyroid and Breast Surgery, Shenzhen Key Laboratory for Endogenous Infection, \\ Shenzhen Nanshan District People's Hospital (The Sixth People's Hospital of Shenzhen), \\ Shenzhen, Guangdong 518052, P.R. China; ${ }^{2}$ Cancer Center, Georgia Regents University, \\ Augusta, GA 30912, USA; ${ }^{3}$ Department of Human Resource, ${ }^{4}$ Clinical Laboratory, \\ Shenzhen Nanshan District People's Hospital; ${ }^{5}$ Department of General Surgery, \\ Zhujiang Hospital, Southern Medical University, Guangzhou, Guangdong 510282, P.R. China
}

Received October 17, 2015; Accepted November 24, 2015

DOI: 10.3892/or.2015.4535

\begin{abstract}
All-trans retinoic acid (ATRA) has been shown to enhance the expression of connexin $43(\mathrm{Cx} 43)$ and the bystander effect (BSE) in suicide gene therapy. These in turn improve effects of suicide gene therapies for several tumor types. However, whether ATRA can improve BSE remains unclear in suicide gene therapy for breast cancer. In the present study, MCF-7, human breast cancer cells were treated with ATRA in combination with a VEGFP-TK/CD gene suicide system developed by our group. We found that this combination enhances the efficiency of cell killing and apoptosis of breast cancer by strengthening the BSE in vitro. ATRA also promotes gap junction intercellular communication (GJIC) in MCF-7 cells by upregulation of the connexin 43 mRNA and protein in MCF-7 cells. These results indicate that enhancement of GJIC by ATRA in suicide gene system might serve as an attractive and cost-effective strategy of therapy for breast cancer cells.
\end{abstract}

\section{Introduction}

Currently there is no effective treatment for patients with breast cancer in an aggressive phase. Breast cancer is caused by complex biological processes involving multi-gene mutations. Therefore any breakthrough in breast cancer treatment is likely to depend on improvement of gene therapy and development of new targeting drugs. Cytosine deaminase/5fluorocytosine (CD/5-FC) and thymidine kinase/ganciclovir

Correspondence to: Dr Heng Kong, Department of Thyroid and Breast Surgery, Nan Shan District People's Hospital, 89 Taoyuan Road, Shenzhen, Guangdong 518052, P.R. China

E-mail: generaldoc@126.com

Key words: breast cancer, All-trans retinoic acid, gap junction intercellular communication, connexin 43 , bystander effect
(TK/GCV) are the most common suicide gene therapy treatment systems $(1,2)$. Single suicide gene therapy often results in tumor relapse and combination gene therapy may potentially overcome the limitations of single gene therapy and improve the therapeutic efficacy $(3,4)$. Our previous study confirmed that the double suicide gene system $(\mathrm{CD} / \mathrm{TK})$ driven by VEGF promoter can inhibit proliferation of human breast cancer cells and induce cancer cells apoptosis in vitro (5) yet even this strategy does not completely eradicate advanced tumors often seen in clinic.

It is well-known now that bystander effect (BSE) is very helpful in promoting the effectiveness of suicide gene system for anticancer therapy. Bystander effect elicits its effect mainly through gap junction-mediated intercellular communication (GJIC) (6). Gap junctions are an important gateway of information exchange by promoting transport of small $(\sim 1 \mathrm{kDa})$ molecules like ions or secondary messengers like cyclic AMP. A gap junction is composed of two connexons, also termed hemichannels, and each connexon is composed of six connexin sub-units (7,8). Three connexins (Cx43, Cx26 and Cx32) have been shown to be expressed in the human breast tissue in different temporal and spatial patterns. In normal human breast tissues, Cx26 and Cx32 are present in the mammary epithelium, whereas $\mathrm{Cx} 43$ is localized mainly to myoepithelial cells $(9,10)$. It was reported that Cxs are often reduced or lost resulting in significantly decreased GJIC in tumor tissues, thus decreased gap junctional communication may be involved in oncogenesis (11). Studies have shown that human mammary tumor MCF-7 cell line has low expression of these connexins, particularly $\mathrm{Cx} 43$ (12). This suggests that MCF-7 cells may regulate GJIC by downregulation of gap junction proteins. Several chemicals [like ATRA, cAMP, and carotenoids (13)] are known for their induction of $\mathrm{Cx} 43$ expression and, subsequently, improvement of GJIC that consequently leads to an increased bystander effect seen in suicide gene therapy.

In this study we selected ATRA because it is strong inducer of GJIC in suicide gene therapy (14). ATRA is a derivative of vitamin A thus is non-toxic and well tolerated in vivo. We 
observed that ATRA significantly improved bystander effect and cell apoptosis in suicide gene therapy for breast cancer MCF-7 cells due to upregulation of Cx43 expression and consequently GJIC. The purpose of our study was to find a more efficient strategy for improving the efficacy of suicide gene therapy for breast cancer.

\section{Materials and methods}

Human breast cancer cell lines. MCF-7 cells were obtained from the American Type Culture Collection (ATCC, VA, USA). They were maintained in a monolayer culture in DMEM (Dulbecco's modified Eagle's medium) with $10 \%$ fetal bovine serum and $0.5 \%$ penicillin/streptomycin. The cells were kept in humidified atmosphere of $5 \% \mathrm{CO}_{2}$ at $37^{\circ} \mathrm{C}$.

Adenovirus vectors and viral infection. The adenovirus vectors (Ad-VEGFP-CD/TK) had previously been constructed by our group and successfully amplified by transient transfection of HEK-293 cells according to published protocols (15). The titer of Ad-VEGFP-CD/TK stock was $2.2 \times 10^{11} \mathrm{pfu} / \mathrm{ml}$ analyzed by end-point dilution assay (16). MCF-7 cells at logarithmic growth phase were incubated in DMEM medium with $10 \%$ FBS containing the adenovirus vectors at multiplicities of infection (MOI) of $20,40,60,80,100$ and 200 at $37^{\circ} \mathrm{C}$ for $24 \mathrm{~h}$. The adenovirus vectors contained green fluorescent protein (GFP) gene as a marker of transduction. Infected cells were analyzed for percentage of GFP-positive cells by flow cytometry (FACS, Becton-Dickinson, San Jose, CA, USA). MCF-7 cells infected by the adenovirus vectors were termed as MCF-7/CD-TK.

Cell viability MTT assay. The MCF-7 cells and MCF-7/CD-TK cells were collected at logarithmic growth phase $\left(1 \times 10^{5} / \mathrm{ml}\right)$. MCF-7/CD-TK cells were trypsinized and mixed with uninfected MCF-7 cells at ratios of $0,5,10,20,40$ and $80 \%$. Then, the cells were seeded at a density of $1 \times 10^{4}$ cells/well in 96-well plates and incubated in DMEM at $37^{\circ} \mathrm{C}$ for $24 \mathrm{~h}$, with or without $10^{-8}$ and $10^{-7} \mathrm{~mol} / \mathrm{l}$ of ATRA. The following day, GCV (final concentration, $1 \mathrm{mg} / \mathrm{l}$ ) and 5-FC (final concentration at $80 \mathrm{mg} / \mathrm{l}$ ) were added in triplicate into the 96 -well plates and further cultured for 2 days. Finally, the cell viability was assessed using 3-(4,5-dimethylthiazol-2-yl)-2,5-diphenyltetrazolium bromide (MTT) (Sigma, St. Louis, MO, USA) assay. MTT was added at a final concentration of $0.5 \mathrm{mg} / \mathrm{ml}$ for $4 \mathrm{~h}$ at $37^{\circ} \mathrm{C}$. After incubation, the supernatant was removed and replaced by DMSO. After the cell plates were shaken for $10 \mathrm{~min}$, cell proliferation was measured in terms of optical absorbance per well by a microplate reader at a wavelength of $490 \mathrm{~nm}$.

Cell apoptosis assay. To investigate the effect of ATRA on apoptosis in Ad-VEGFP-CD/TK suicide gene, we used JC-1 Assay kit (17) (Molecular Probes, Eugene, OR, USA) which measures the integrity of mitochondria. MCF-7/CD-TK cells were mixed with non-transduced parental cells at ratios of 2:3. Cells were seeded at a density of $1 \times 10^{6}$ cells in a $25-\mathrm{cm}^{2}$ culture bottle and incubated in DMEM at $37^{\circ} \mathrm{C}$ for $24 \mathrm{~h}$, with or without $10^{-8}$ and $10^{-7} \mathrm{~mol} / \mathrm{l}$ ATRA. The following day, GCV $(1 \mathrm{mg} / \mathrm{l})$ and 5 -FC (80 mg/l) were added to cells for 2 days.
Pure MCF-7 cells in the control group were cultured in DMEM for 2 days. Then, the cells were collected and incubated with JC-1 working solution (JC-1 stock solution and assay buffer at a 1,100$)$ at $37^{\circ} \mathrm{C}$ in the dark for $20 \mathrm{~min}$. Cells were then collected by centrifugation at room temperature and washed twice with PBS. Apoptosis was measured a flow cytometry (Beckman Coulter, USA) to detect 5, 5', 6, 6'-tetrachloro1, 1', 3, 3'-tetraethyl-benzimidazolylcarbocyanine iodide (JC-1) staining, which emits green fluorescence (detected in FL1 channel) when it is in monomer (indication of cell apoptosis) and red (detected in FL2 channel) when it aggregates (which detects healthy cells). Apoptosis was indicated by an increase in the green/red fluorescence intensity ratio (18).

Flow cytometry analysis of GJIC in MCF-7 cells under ATRA treatment. GJIC was functionally evaluated by means of flow cytometry, as described by Peterson-Roth et al (19). MCF-7 $\left(3 \times 10^{5}\right)$ cells per well were seeded into 6 -well plates. The next day, ATRA was added to MCF-7 cells at $10^{-8}$ or $10^{-7} \mathrm{~mol} / 1$ ATRA for the next $72 \mathrm{~h}$. Cells without added ATRA served as a control. The donor cells were preloaded with fluorescent dyes calcein/AM (Molecular Probes) and 1,10-dioctadecyl3,3,30,30-tetramethylindocarbocyanine perchlorate (DiI) (Molecular Probes) for $20 \mathrm{~min}$ in a $5 \% \mathrm{CO}_{2}$ incubator at $37^{\circ} \mathrm{C}$. After ATRA treatment for $72 \mathrm{~h}$, the preloaded donor cells were added to the unlabeled recipient cells at a ratio of 1:50 and were co-cultured for $5 \mathrm{~h}$ in the presence of ATRA. After incubation, cells were collected by trypsinization, washed and resuspended in PBS and analyzed by flow cytometer. Data were analyzed by flow analysis software (FACSAria, FACSDiva Software, BD Biosciences, NJ, USA).

Real-time RT-PCR. MCF-7 cells were incubated in DMEM with $10^{-8}$ or $10^{-7} \mathrm{~mol} / 1$ ATRA at $37^{\circ} \mathrm{C}$ for $72 \mathrm{~h}$. The control group was decoid of ATRA. Total RNA from experimental and control group was prepared using the TRIzol reagent (Invitrogen, Carlsbad, CA, USA) according to the manufacturer's instructions. RT-PCR was performed on $0.5 \mu \mathrm{g}$ total RNA using a QuantiTect Rev Transcription kit (Qiagen). Quantitative PCR was performed using an ABI 7500 Real-Time PCR system and a QuantiTect SYBR Green PCR kit (Qiagen); $\beta$-actin was used as an endogenous reference, and each sample was normalized to its $\beta$-actin content. All experiments were performed in duplicate and repeated twice. Primers for quantitative PCR are shown in Table I.

Flow cytometry analysis of Cx43 expression. MCF-7 cells were seeded at a density of $5 \times 10^{5}$ cells/well in a $50-\mathrm{ml}$ cell culture bottle and incubated in DMEM at $37^{\circ} \mathrm{C}$ for $24 \mathrm{~h}$. Cells were infected with Ad-VEGFP-CD/TK vector for $24 \mathrm{~h}$ following exposure to ATRA $\left(0,10^{-8}\right.$ and $\left.10^{-7} \mathrm{~mol} / \mathrm{l}\right)$ for $72 \mathrm{~h}$. Cells were then trypsinized, collected, and re-suspended in cold PBS $\left(10^{6}\right.$ cells $\left./ \mathrm{ml}\right)$. Polyclonal anti-Cx43 antibody (1:1,000, ProteinTech Group, Chicago, IL, USA) was added to cells for $30 \mathrm{~min}$ and cells were stained on ice. Cells were washed in FACS buffer (PBS+2\% FBS) and FITC-labeled goat anti-rabbit IgG (1:500, Molecular Probes) was added or $30 \mathrm{~min}$ on ice. Cells were centrifuged and washed with PBS. The cells were harvested and analysis was performed using a Beckman Coulter Flow Cytometer (Beckman Coulter). The 
Table I. Primer set used for real-time PCR.

\begin{tabular}{llc}
\hline Primer set & \multicolumn{1}{c}{ Sequence } & Target gene \\
\hline qCx43 & Sense: 5'-AAATAGACAGGTCTGAGTGCCTGAA-3' & Homo sapiens gap junction \\
& Antisense: 5'-CCTCCAGCAGTTGAGTAGGCTTG-3' & protein (NM_000165.4) \\
& & Amplicon: 181 bp \\
q $\beta$-actin & Sense: 5'-TGGCACCCAGCACAATGAA-3' & Actin, $\beta$ (NM_001101) \\
& Antisense: 5'-CTAAGTCATAGTCCGCCTAGAAGCA-3' & Amplicon: 186 bp \\
\hline
\end{tabular}

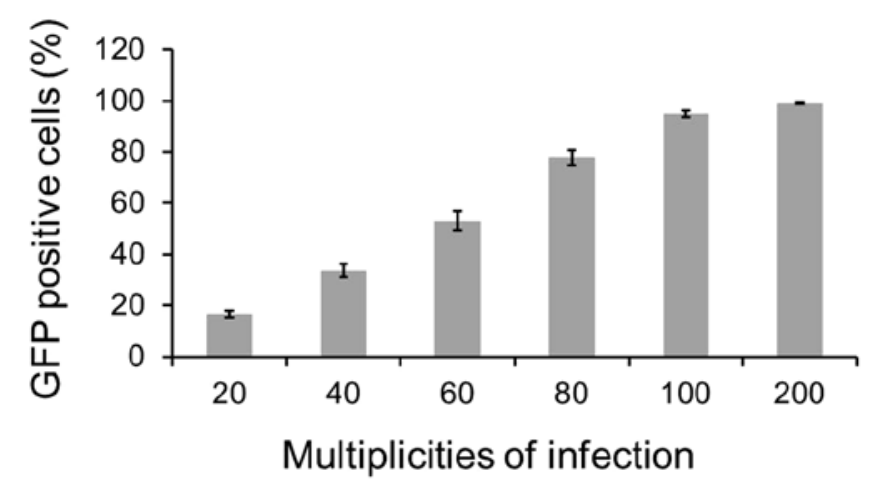

Figure 1. The efficiency of infection in MCF-7 cells by Ad-VEGFP-CD/TK with flow cytometry analysis.

data were analyzed by Multicycle software (Phonenix Flow Systems, USA).

Statistics. All data were expressed as means \pm SD and analyzed with SPSS version 16.0. A Dunnett's t-test and a one-way ANOVA were performed to assess the statistical significance between different groups. Significance for all tests was established at $\mathrm{p}<0.05$.

\section{Results}

Infection efficiency of Ad-VEGFP-CD/TK in MCF-7 breast cancer cells. As shown in Fig. 1, one day after infection, $>16 \%$ of GFP-MCF-7 cells at a MOI of 20 were identified by flow cytometry. The infected GFP-positive cells were as high as $95.05 \%$ at MOI of 100 . More than $99 \%$ of the infected cells expressed green fluorescence at an MOI of 200. The result indicated that the Ad-VEGFP-CD/TK vector was able to effectively infect MCF-7 cells in vitro.

Effect of ATRA on prodrug cytotoxicity. ATRA at a final concentration of $10^{-7}$ and $10^{-8} \mathrm{~mol} / \mathrm{l}$ had no toxicity to MCF-7 cells. This concentration was established based on previous studies (20). We detected the ability of ATRA $\left(10^{-7}\right.$ and $\left.10^{-8} \mathrm{~mol} / \mathrm{l}\right)$ to enhance the bystander effect of our suicide gene system in mixed cultures of transgenic and non-transgenic cells at various ratios. As shown in Fig. 2, the MTT assays showed 79, 57, 52, 40 and $34 \%$ cell viability after prodrug and ATRA $\left(10^{-7} \mathrm{~mol} / \mathrm{l}\right)$ treatment for a ratio of 5, 10, 20, 40 and $80 \%$ infected cells, respectively, and $83,66,60,50$ and $38 \%$ cell viability after prodrug and ATRA $\left(10^{-8} \mathrm{~mol} / \mathrm{l}\right)$ treatment,

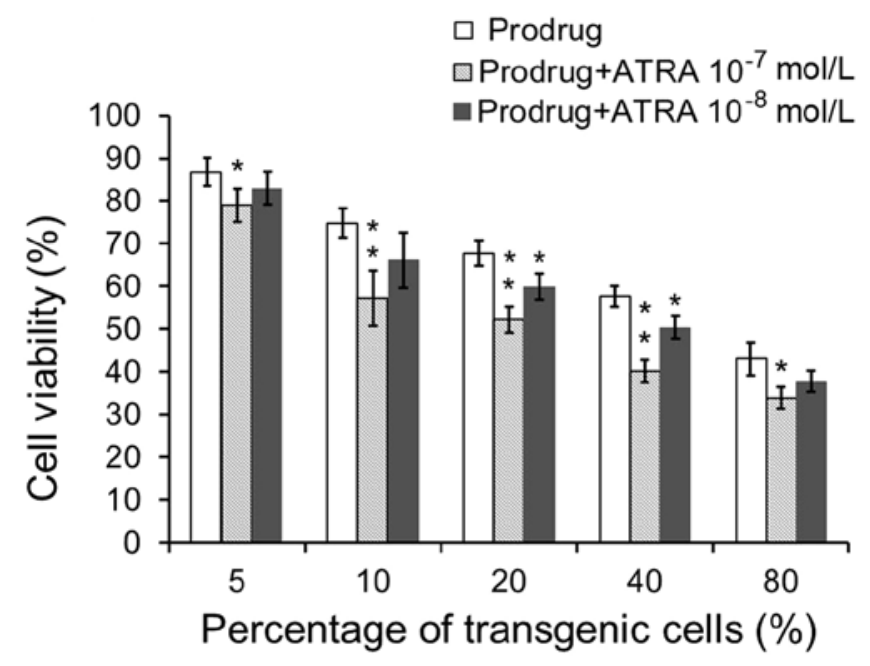

Figure 2. Augmented bystander effect of Ad-VEGFP-CD/TK suicide gene system combined with ATRA on different proportions of transgenic MCF-7 cells with MTT assay. ${ }^{*} \mathrm{p}<0.05$ and ${ }^{* *} \mathrm{p}<0.01$, compared with control group (prodrug).

respectively, and $87,75,68,58$ and $43 \%$ cell viability after prodrug alone treatment, respectively. The data showed that MCF-7 cell survival rate decreased along with the increasing ratios of $\mathrm{CD} / \mathrm{TK}$-transgenic cells. This result indicates that bystander effects exist in MCF-7 cells exposed to suicide gene system. In addition, the cell survival rate under treatment with the prodrug (5-FC and GCV) and ATRA $\left(10^{-7} \mathrm{~mol} / \mathrm{l}\right)$ was significantly lower than those of the cells treated with the prodrug alone $(\mathrm{p}<0.05)$. In addition, the cell survival rate in the treatment with the prodrug and ATRA $\left(10^{-8} \mathrm{~mol} / \mathrm{l}\right)$ was significantly lower than the prodrug alone at ratios of 1:5 and $2: 5$, of the infected cells to the non-infected cells $(\mathrm{p}<0.05)$. The result demonstrates ATRA can promote the bystander effects of the suicide gene system for breast cancer cells.

Effect of ATRA on apoptosis of breast cancer cells. When transgenic MCF-7 cells were mixed with non-transgenic MCF-7 cells at ratios of $40 \%$ and treated by prodrug and/or the ATRA, there was a significantly different apoptosis rate between the prodrug only group and ATRA plus the prodrug group (Fig. 3). In control group, MCF-7 cells showed a low rate of apoptosis of $5.45 \%$. Under the treatment of 5-FC and GCV, cell apoptosis rate was $15.50 \%$. Under the combined treatment of the prodrug and ATRA (the concentration of ATRA was 

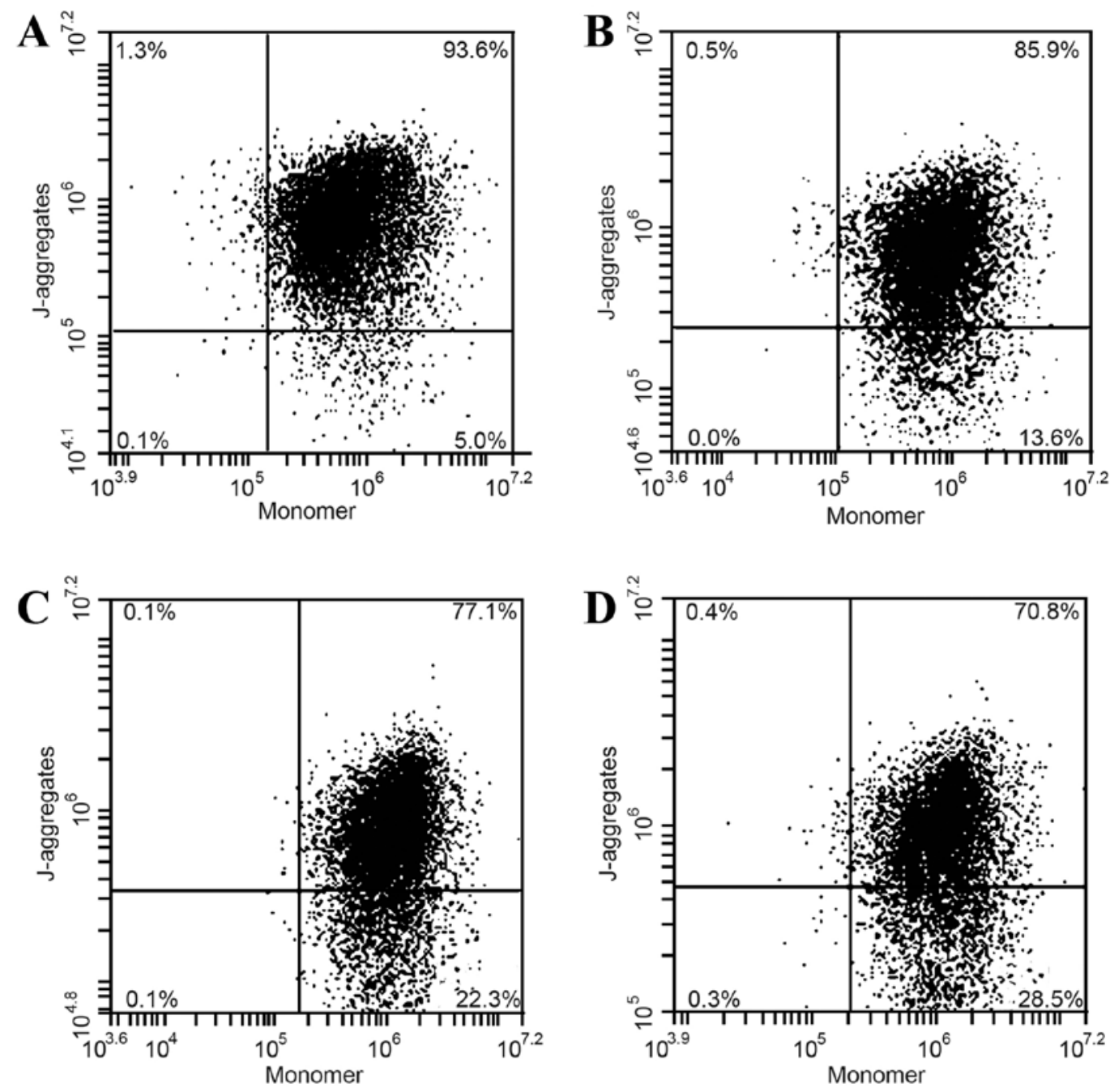

$\mathbf{E}$

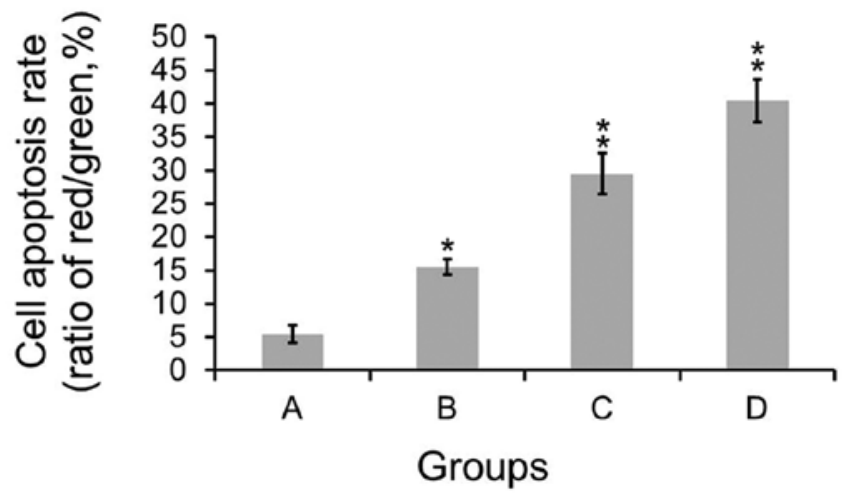

Figure 3. Flow cytometric percentage and histogram of MCF-7 cell apoptosis rates detected by JC-1 dye. (A) Control; (B) GCV (1 mg/l) and 5-FC (80 mg/l); (C) ATRA $10^{-8} \mathrm{~mol} / 1+\mathrm{GCV}(1 \mathrm{mg} / \mathrm{l})$ and 5-FC $(80 \mathrm{mg} / \mathrm{l})$; (D) ATRA $10^{-7} \mathrm{~mol} / 1+\mathrm{GCV}(1 \mathrm{mg} / \mathrm{l})$ and 5-FC (80 mg/l); (E) Histogram of MCF-7 cell apoptosis rates in (A), (B), (C) and (D) groups $\left(* \mathrm{p}=0.001,{ }^{* *} \mathrm{p}<0.001\right)$.

$10^{-8} \mathrm{~mol} / \mathrm{l}$ or $\left.10^{-7} \mathrm{~mol} / \mathrm{l}\right)$, cell apoptosis rate was 29.48 and $40.46 \%$, respectively. The results indicate that there is statistically significant difference among four groups $(\mathrm{F}=125.277)$. The data suggested that the prodrug only exerted some cell killing effects in mixed cells. The apoptotic rate was significantly increased with the addition of ATRA, especially when the concentration of ATRA increased from $10^{-8} \mathrm{~mol} / 1$ to $10^{-7} \mathrm{~mol} / \mathrm{l}$. The effect of ATRA showed a concentrationdependent manner. These results demonstrated that the drug plus ATRA therapy was superior to prodrug only.

Impact of ATRA on GJIC. To detect the change in GJIC caused by ATRA in MCF-7 cells, we used flow cytometry quantification of calcein/CM-DiI assays. DiI cannot pass through gap 
A

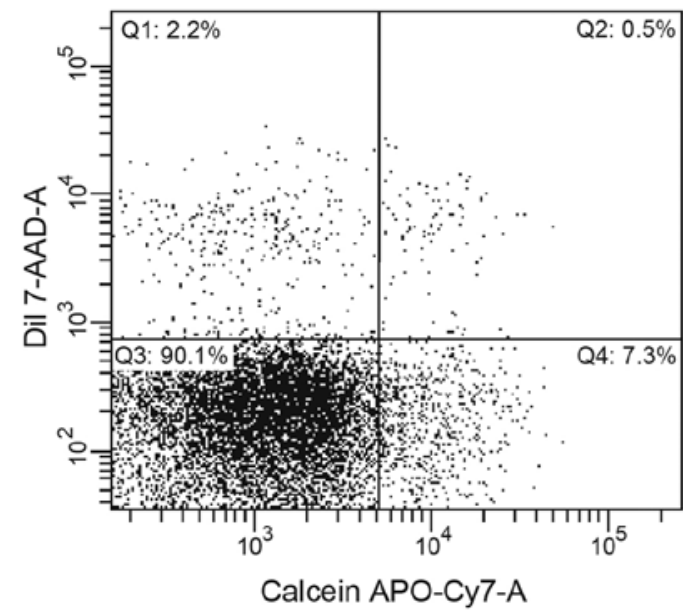

C

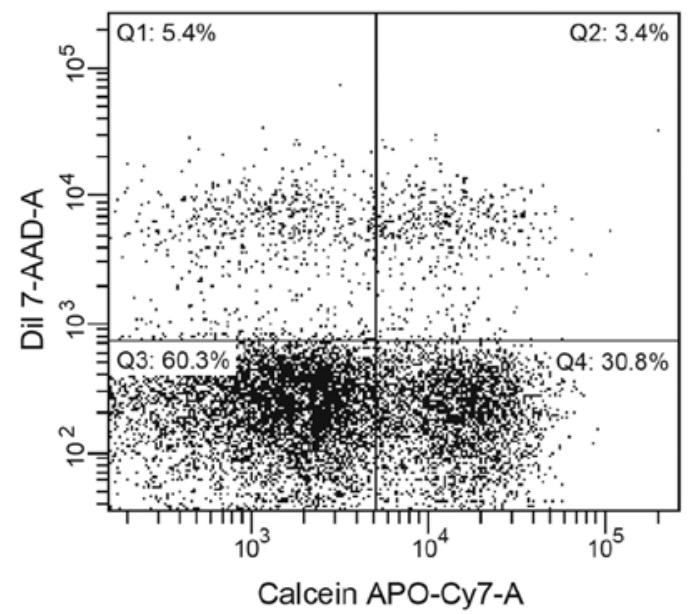

B

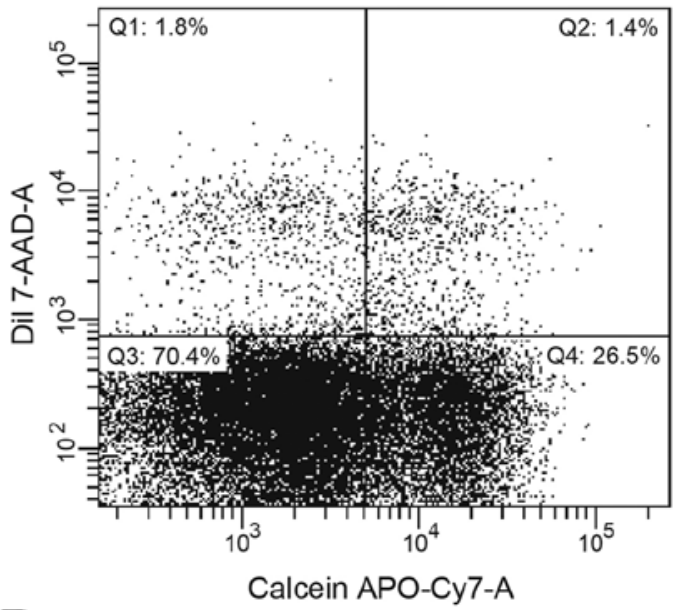

D

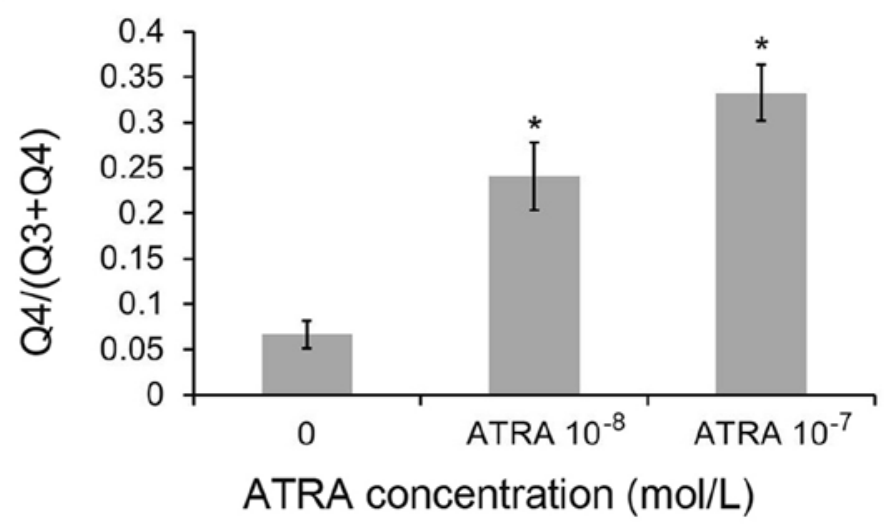

Figure 4. ATRA promotes GJIC of MCF-7 cells analyzed by flow cytometry. (A) Control; (B) ATRA 10 ${ }^{-8}$ mol/1; (C) ATRA 10 ${ }^{-7}$ mol/1; (D) Histogram of the ratio of $\mathrm{Q} 4$ to $(\mathrm{Q} 3+\mathrm{Q} 4)$ in $(\mathrm{A}),(\mathrm{B})$ and $(\mathrm{C})$ groups $\left({ }^{*} \mathrm{p}<0.01\right.$, ATRA groups vs control group).

junctions, while calcein passes through gap junctions and transfer cells preloaded with calcein to a population of unloaded cells. In the FACS plot (Fig. 4), quadrants Q1 represents cell populations positive for DiI, and the cells population in quadrants Q2 represents preloaded cells which are positive for both dyes, and the population in quadrants Q4 represents positive cells for only calcein which are the unlabeled cells that received the calcein dye through GJIC. The population in quadrants Q3 represents the calcein-negative unlabeled cells. The ratio of MCF-7 cell numbers in quadrants Q4 to Q3 plus Q4 was used to evaluate the transfer of calcein as an indication of GJIC function. As seen in Fig. 4D, the ratio of Q4 to (Q3+Q4) was $0.07,0.24$ and 0.33 in the control group, $10^{-8}$ and $10^{-7} \mathrm{~mol} / 1$ ATRA treatment group, respectively $(\mathrm{p}<0.01)$. The results show that ATRA significantly increased GJ transmission in MCF-7 cells in a concentration-dependent manner, which indicates GJIC function in the MCF-7 cells is significantly improved by ATRA treatment.

ATRA treatment upregulates connexin 43 gene expression. Our previous experiment indicated increased GJIC being an effect of treatment with ATRA. It was crucial to delineate whether it is a sole enhancement in the intercellular communication or whether this is an effect on increased gap junctions resulting with increased expression of $\mathrm{Cx} 43$. Transgenic MCF-7 cells were treated with increasing concentrations of ATRA $\left(0,10^{-7}\right.$ and $\left.10^{-8} \mathrm{~mol} / \mathrm{l}\right)$ for $72 \mathrm{~h}$ to determine the ATRA effect on the expression of $\mathrm{Cx} 43$ gene by real-time PCR. The upregulation of the $\mathrm{Cx} 43$ gene was pronounced, yielding a 1.5-fold increase $\left(10^{-8} \mathrm{~mol} / 1\right.$ ATRA $)$ and 3.6-fold $\left(10^{-7} \mathrm{~mol} / 1\right.$ ATRA), respectively. Furthermore, the results indicate that the influence is dose-dependent. Compared with levels in control group, the mRNA expression levels of $\mathrm{Cx} 43$ in the transgenic MCF-7 cells treated with ATRA were increased significantly $(\mathrm{p}<0.01$, Fig. 5).

Flow cytometry analysis of Cx43 protein expression in $M C F-7$ cells. To examine whether or not $\mathrm{Cx} 43$ protein expression in MCF-7-CD/TK cells changes under the influence of ATRA, different concentrations of ATRA $\left(0,10^{-7}\right.$ and $\left.10^{-8} \mathrm{~mol} / \mathrm{l}\right)$ were added to cultures of MCF-7 cells. Flow cytometry analysis showed that positive rates of $\mathrm{Cx} 43$ protein expression in transgenic MCF-7 treated with the different concentrations 


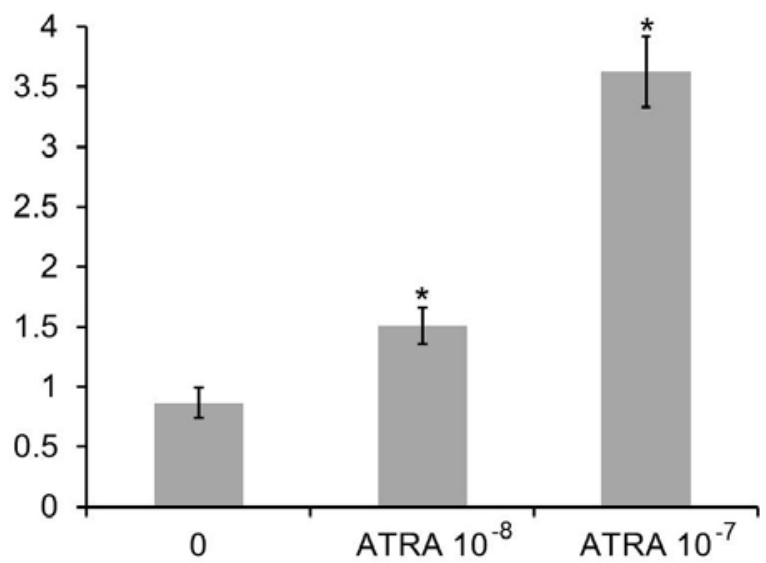

ATRA concentration ( $\mathrm{mol} / \mathrm{L})$

Figure 5. Relative expression of mRNA levels of $\mathrm{Cx} 43$ in MCF-7 cells treated by different concentration of ATRA $\left({ }^{*} \mathrm{p}<0.01\right.$, ATRA groups vs control group).

A

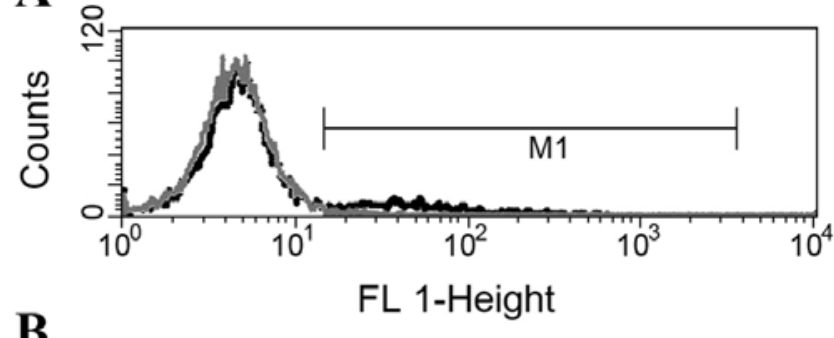

B

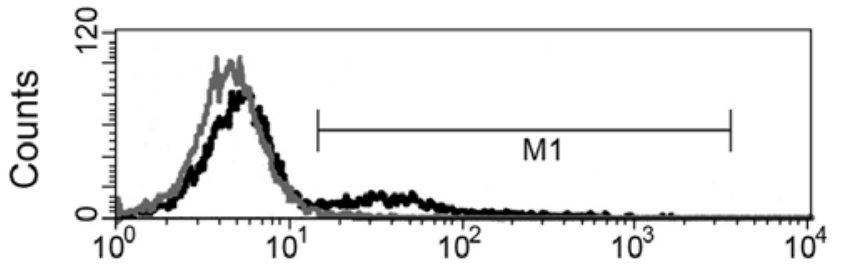

FL 1-Height

C

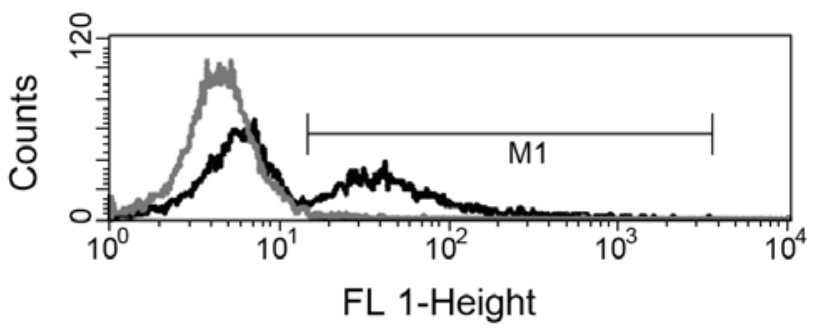

Figure 6. Flow cytometry analysis of $\mathrm{Cx} 43$ expression in transgenic MCF-7 cells under ATRA treatment. (A) Control group; (B) ATRA $10^{-8} \mathrm{~mol} / \mathrm{l}$; (C) ATRA $10^{-7} \mathrm{~mol} / \mathrm{l}$.

of $0,10^{-8}$ or $10^{-7} \mathrm{~mol} / 1$ ATRA were $(6.27 \pm 1.75),(15.58 \pm 1.41)$ and $(27.32 \pm 2.85) \%$, respectively. A significant difference was noted between the experimental group $\left(10^{-8}\right.$ or $10^{-7} \mathrm{~mol} / 1$ ATRA) and the untreated control group. As shown in Fig. 6, at $72 \mathrm{~h}$ after ATRA exposure, the percentages of $\mathrm{Cx} 43$ protein detected using flow cytometry were also significantly higher in cells of the experimental group than in the control cells both transfected with Ad-VEGFP-CD/TK vector.

\section{Discussion}

Suicide gene therapy is a potential way of targeting cancer, which is much less harmful to healthy cells. Many studies also have achieved good results in the application of suicide gene system in multiple malignancy tumors, such as glioblastoma, prostate cancer, and breast cancer (21-23). Moreover, some clinical trial of suicide gene therapy for patients with certain malignant tumors showed encouraging effects $(24,25)$. However, the efficacy of the suicide gene therapy for the treatment of cancer is limited because of the low killing activity. The bystander effect in suicide gene therapy offers a way of promoting the effectiveness of suicide gene system for cancer. ATRA can enhance $\mathrm{Cx} 43$ expression and upregulate GJIC in various tumor cells. To enhance the antitumor activity, we determined whether suicide gene system combined with ATRA could potentiate the destruction of breast cancer.

Three connexin proteins have been identified in breast tissues, including Cx43, Cx26 and Cx32 (9). Expression of $\mathrm{Cx} 26$ and $\mathrm{Cx} 32$ are enhanced during pregnancy and further increased during lactation in normal breast tissues (10). $\mathrm{Cx} 43$ is the most widely studied of these connexin proteins because of its high expression in many cells (26) including breast cancer cells although human MCF-7 cells express low level of GJIC (12). In this study, QPCR and FACS methods detected upregulation of $\mathrm{Cx} 43$ gene and protein in MCF-7 cells under ATRA treatment. At the same time, ATRA was found to significantly increase GJ transmission in MCF-7 cells as a results of ATRA elevated $\mathrm{Cx} 43$ expression.

In the present study, we observed that the cell survival rate of transgenic MCF-7 cells treated with the prodrug and ATRA was significantly lower than those of the cells treated with the prodrug alone $(\mathrm{p}<0.05)$. Our findings suggest that the therapeutic bystander effect of VEGFP-TK/CD system in MCF-7 cells was enhanced by combination with ATRA administration via overexpression of $\mathrm{Cx} 43$ and enhanced GJIC. We also found that compared with control group, the suicide gene system induced a marked increase in cell apoptosis rate in MCF-7 cells under the prodrug plus ATRA treatment group when MCF-7/CD-TK cells were mixed with non-transgenic MCF-7 cells at ratios of $40 \%$. Intercellular communication through gap junctions plays an important role in maintaining tissue homeostasis by allowing transfer of ions and small molecules (molecular weight $<1 \mathrm{kDa}$ ) by GJIC (27). So, the present study suggested that the transfer of apoptotic vesicles from dying cells to the surrounding non-transgenic tumor cells through gap junctions is one of the mechanistic actions of the suicide gene system on the BSE in cancer cells.

In conclusion, we demonstrated that ATRA can augment bystander effect and increase apoptosis in MCF-7 cells during suicide gene therapy against breast cancer. The effect was associated with enhanced GJIC via the upregulation of $\mathrm{Cx} 43$ expression driven by ATRA induction. Our study suggested the upregulation of gap junctional communication by ATRA may provide a novel pathway of chemical inducer for improving suicide gene system therapy for breast cancer. 


\section{Acknowledgements}

This study was supported by Shenzhen Council for Scientific and Technological Innovation under grant JCYJ20130402151227177 and Shenzhen Nanshan District Science and Technology Project under grant 2015009.

\section{References}

1. Nguyen Thai QA, Sharma N, Luong H, Sodhi SS, Kim JH, Kim N, Oh SJ and Jeong DK: Targeted inhibition of osteosarcoma tumor growth by bone marrow-derived mesenchymal stem cells expressing cytosine deaminase/5-fluorocytosine in tumorbearing mice. J Gene Med 17: 87-99, 2015.

2. Zu B, Shi Y, Xu M, You G, Huang Z, Gao M and Feng W: ARE/ SUZ12 dual specifically-regulated adenoviral TK/GCV system for CML blast crisis cells. J Exp Clin Cancer Res 34: 56, 2015.

3. Niu J, Xing C, Yan C, Liu H, Cui Y, Peng H, Chen Y, Li D, Jiang C, $\mathrm{Li} \mathrm{N}$, et al: Lentivirus-mediated CD/TK fusion gene transfection neural stem cell therapy for C6 glioblastoma. Tumour Biol 34: 3731-3741, 2013.

4. Ibrišimović M, Lion T and Klein R: Combinatorial targeting of 2 different steps in adenoviral DNA replication by herpes simplex virus thymidine kinase and artificial microRNA expression for the inhibition of virus multiplication in the presence of ganciclovir. BMC Biotechnol 13: 54, 2013.

5. Kong H, Tao L, Qi K, Wang Y, Li Q, Du J and Huang Z: Thymidine kinase/ganciclovir and cytosine deaminase/5-fluorocytosine suicide gene therapy-induced cell apoptosis in breast cancer cells. Oncol Rep 30: 1209-1214, 2013.

6. Sato T, Neschadim A, Lavie A, Yanagisawa T and Medin JA: The engineered thymidylate kinase (TMPK)/AZT enzyme-prodrug axis offers efficient bystander cell killing for suicide gene therapy of cancer. PLoS One 8: e78711, 2013.

7. Gabashvili AN, Baklaushev VP, Grinenko NF, Levinskii AB, Mel'nikov PA, Cherepanov SA and Chekhonin VP: Functionally active gap junctions between connexin 43-positive mesenchymal stem cells and glioma cells. Bull Exp Biol Med 159: 173-179, 2015.

8. Vaiyapuri S, Flora GD and Gibbins JM: Gap junctions and connexin hemichannels in the regulation of haemostasis and thrombosis. Biochem Soc Trans 43: 489-494, 2015.

9. Rakib MA, Lee WS, Kim GS, Han JH, Kim JO and Ha YL: Antiproliferative action of conjugated linoleic acid on human MCF-7 breast cancer cells mediated by enhancement of gap junctional intercellular communication through inactivation of NF- $\kappa$ B. Evid Based Complement Alternat Med 2013: 429393, 2013.

10. Stewart MK, Plante I, Bechberger JF, Naus CC and Laird DW: Mammary gland specific knockdown of the physiological surge in Cx26 during lactation retains normal mammary gland development and function. PLoS One 9: e101546, 2014.

11. Yang J, Liu B, Wang Q, Yuan D, Hong X, Yang Y and Tao L: Connexin 32 and its derived homotypic gap junctional intercellular communication inhibit the migration and invasion of transfected HeLa cells via enhancement of intercellular adhesion. Mol Med Rep 4: 971-979, 2011.

12. Talhouk RS, Fares MB, Rahme GJ, Hariri HH, Rayess T, Dbouk HA, Bazzoun D, Al-Labban D and El-Sabban ME: Context dependent reversion of tumor phenotype by connexin-43 expression in MDA-MB231 cells and MCF-7 cells: Role of $\beta$-catenin/connexin43 association. Exp Cell Res 319: 3065-3080, 2013.
13. Piccoli C, D'Aprile A, Scrima R, Ambrosi L, Zefferino R and Capitanio N: Subcytotoxic mercury chloride inhibits gap junction intercellular communication by a redox- and phosphorylationmediated mechanism. Free Radic Biol Med 52: 916-927, 2012.

14. Hu C, Chen Z, Zhao W, Wei L, Zheng Y, He C, Zeng Y and Yin B: Vesicular stomatitis virus $G$ glycoprotein and ATRA enhanced bystander killing of chemoresistant leukemic cells by herpes simplex virus thymidine kinase/ganciclovir. Biomol Ther (Seoul) 22: 114-121, 2014

15. Chen JF, Huang ZH, Huang YY, Song HJ and Che XY: Construction of recombinant adenoviruses encoding TK suicide gene driven by VEGF promoter using efficient AdEasier-1 system. Ai Zheng 23: 1093-1097, 2004 (In Chinese).

16. Sugiyama N, Murayama A, Suzuki R, Watanabe N, Shiina M, Liang TJ, Wakita T and Kato T: Single strain isolation method for cell culture-adapted hepatitis $\mathrm{C}$ virus by end-point dilution and infection. PLoS One 9: e98168, 2014.

17. Wang J, Zhao YM, Zhang B and Guo CY: Protective effect of total phenolic compounds from Inula helenium on hydrogen peroxide-induced oxidative stress in SH-SY5Y Cells. Indian J Pharm Sci 77: 163-169, 2015.

18. Abu N, Akhtar MN, Yeap SK, Lim KL, Ho WY, Zulfadli AJ, Omar AR, Sulaiman MR, Abdullah MP and Alitheen NB: Flavokawain A induces apoptosis in MCF-7 and MDA-MB231 and inhibits the metastatic process in vitro. PLoS One 9: e105244, 2014.

19. Peterson-Roth E, Brdlik CM and Glazer PM: Src-Induced cisplatin resistance mediated by cell-to-cell communication. Cancer Res 69: 3619-3624, 2009.

20. Stefanska B, Salamé P, Bednarek A and FabianowskaMajewska K: Comparative effects of retinoic acid, vitamin D and resveratrol alone and in combination with adenosine analogues on methylation and expression of phosphatase and tensin homologue tumour suppressor gene in breast cancer cells. Br J Nutr 107: 781-790, 2012.

21. de Melo SM, Bittencourt S, Ferrazoli EG, da Silva CS, da Cunha FF, da Silva FH, Stilhano RS, Denapoli PM, Zanetti BF, Martin PK, et al: The anti-tumor effects of adipose tissue mesenchymal stem cell transduced with HSV-Tk gene on U-87-driven brain tumor. PLoS One 10: e0128922, 2015.

22. Kubo M, Satoh T, Tabata KI, Tsumura H, Iwamura M, Baba S, Thompson TC and Obata F: Enhanced central memory cluster of differentiation $8(+)$ and tumor antigen-specific $\mathrm{T}$ cells in prostate cancer patients receiving repeated in situ adenovirus-mediated suicide gene therapy. Mol Clin Oncol 3: 515-521, 2015.

23. Yi BR, Choi KJ, Kim SU and Choi KC: Therapeutic potential of stem cells expressing suicide genes that selectively target human breast cancer cells: Evidence that they exert tumoricidal effects via tumor tropism (Review). Int J Oncol 41: 798-804, 2012.

24. Kim KH, Dmitriev I, O'Malley JP, Wang M, Saddekni S, You Z, Preuss MA, Harris RD, Aurigemma R, Siegal GP, et al: A phase I clinical trial of Ad5.SSTR/TK.RGD, a novel infectivityenhanced bicistronic adenovirus, in patients with recurrent gynecologic cancer. Clin Cancer Res 18: 3440-3451, 2012.

25. Maury S, Rosenzwajg M, Redjoul R, Marcais A, Xhaard A, Cherai M, Cabanne L, Churlaud G, Suarez F, Socié G, et al: Lymphodepletion followed by infusion of suicide gene-transduced donor lymphocytes to safely enhance their antitumor effect: A phase I/II study. Leukemia 28: 2406-2410, 2014.

26. Ghosh S, Kumar A and Chandna S: Connexin-43 downregulation in $\mathrm{G} 2 / \mathrm{M}$ phase enriched tumour cells causes extensive low-dose hyper-radiosensitivity (HRS) associated with mitochondrial apoptotic events. Cancer Lett 363: 46-59, 2015.

27. Kleopa KA and Sargiannidou I: Connexins, gap junctions and peripheral neuropathy. Neurosci Lett 596: 27-32, 2015. 